\title{
PREPARAÇÃO E APLICAÇÃO DE ORGANO-MINERAL COMO ADSORVENTE DE ÓLEO/ÁGUA: AVALIANDO O EFEITO DE DIFERENTES MODIFICADORES ORGÂNICOS (CLORETO DE CETIL TRIMETIL AMÔNIO E CLORETO DE ALQUIL DIMETIL BENZIL AMÔNIO)
}

\author{
R. S. S. CUNHA ${ }^{* 1}$; J. D. MOTA ${ }^{1}$; M. G. F. RODRIGUES ${ }^{1}$ \\ ${ }^{1}$ Universidade Federal de Campina Grande - UFCG, Departamento de Engenharia Química \\ Av. Aprígio Veloso 882- Bodocongó - CEP: 58429-970 - Campina Grande - PB - Brasil. \\ Telefone: (83) 2101-1488 - Fax: 2101-1488 \\ E-mail: rocheliachel@hotmail.com
}

\begin{abstract}
RESUMO - A bentonita, composta predominantemente pelo argilomineral montmorilonita que lhe confere as propriedades físicas concentra a maior parte das reservas nacionais (62\%) no Estado da Paraíba. A transformação da bentonita em argila organofílica consiste em ser realizada através de reação de troca dos cátions $\left(\mathrm{Na}^{+}\right.$ou $\left.\mathrm{Ca}^{2+}\right)$ presentes na superfície e no espaço interlamelar dos argilominerais, por cátions de sais quaternários de amônio. Neste trabalho a bentonita organofílica foi preparada utilizando dois tipos diferentes de sais quaternários de amônio, tais como: cloreto de alquil dimetil benzil amônio (Dodigen) e cloreto de cetil trimetil amônio (Genamin). As argilas organofilizadas foram caracterizadas por difração de raios $\mathrm{X}$, inchamento de foster, capacidade de adsorção, e avaliado seu potencial na remoção de emulsões óleo/água. Os resultados confirmaram a incorporação dos sais quaternários de amônio na estrutura da argila e apresentaram elevados percentuais de remoção.
\end{abstract}

\section{INTRODUÇÃO}

A poluição da água por óleo tem deixado um impacto indesejado sobre o meio ambiente. A presença de óleo em água, não só induz efeitos prejudiciais para a vida aquática, mas também causa sérios problemas para estações de tratamento de águas residuais conforme Zhou et al. (2008) e Rajakovic et al. (2007). Geralmente, o petróleo provoca a contaminação da água por duas formas, óleo livre e óleo emulsionado. Óleo livre não é um grande problema, uma vez que o óleo pode ser separado por gravidade. No entanto, o óleo emulsionado apresenta um verdadeiro problema devido à sua estabilidade na fase aquosa. As emulsões de óleo existente nos efluentes são provenientes de várias fontes, tais como refinarias de petróleo, usinas de laminação, plantas de processamento químico e de fabricação conforme Benito (1998).

Existem vários métodos para tratamento de águas residuais oleosas incluindo físico, biológico, química, métodos mecânicos e físico-químicos (ou seja, flutuação), e processos de 


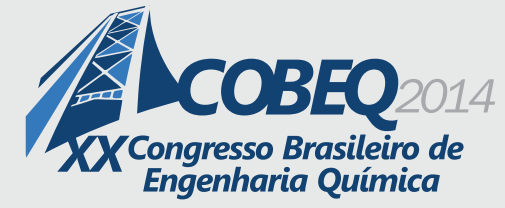

19 a 22 de outubro de 2014

Florianópolis/SC

membrana têm sido desenvolvidos e acordo com Shariff (2010). No entanto, existem muitas limitações para tais tratamentos, como a baixa eficiência, alto custo de operação, a corrosão e a recontaminação de acordo com Zhou et al. (2008).

Com a premissa de buscar novos materiais adsorventes, as argilas esmectíticas surgem como alternativas no processo de adsorção por possuírem elevada área de superfície, alta capacidade de troca catiônica e baixo custo conforme Gil et al., (2011). No entanto as argilas naturais possuem a características de ser hidrofílica o que dificulta a remoção de compostos orgânicos por não possuírem afinidade, porem quando modificadas quimicamente permite seu uso para diversos tipos de aplicações tecnológicas, resultando grande valor científico e industrial Lagaly et al., (2006).

A modificação da característica naturalmente hidrofílica das argilas para organofílica possibilita seu uso como adsorvente de compostos orgânicos como gasolina, óleo diesel, xileno e tolueno, destacando-se na separação de misturas óleo/água. Ramos Vianna (2005), Silva e Ferreira (2007) e Silva et al. (2011) estudaram as propriedades de expansão e adsortivas de argilas organofílicas em diferentes líquidos orgânicos que podem ser encontrados contaminando solos e águas.

Neste trabalho, as argilas organofílicas foram preparadas e utilizando dois tipos de sais quaternários de amônio (surfactantes: GENAMIN CTAC-50 e DODIGEN 1611®) e avaliadas no processo de separação emulsão óleo/água.

\section{MATERIAIS E MÉTODOS}

\subsection{Preparação das argilas organofílicas}

Foi utilizada a argila Bofe, fornecida pela Bentonisa do Nordeste S.A., localizada em Boa Vista, Paraíba. Foram utilizados os sais quaternários de amônio comerciais Cloreto de alquil dimetil benzil amônio (Dodigen 1611®) e Cloreto de cetil trimetil amônio (Genamin) fornecidos pela Clariant. Na Figura 1 é possível observar as estruturas dos sais utilizados na organofilização da argila Bofe:

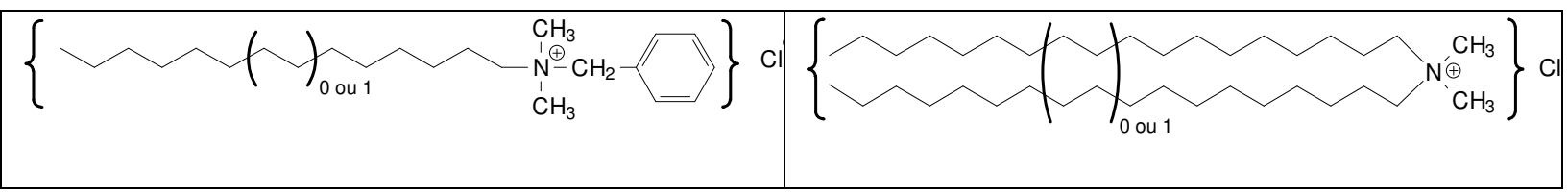

Figura 1- Estruturas dos sais quaternários de amônio: Dodigen e Genamin.

Metodologia de organofilização: Foi utilizado argila com granulometria $0,005 \mathrm{~mm}$, em seguida, preparada uma dispersão aquosa a uma concentração de 4\%, em peso de argila. Esta dispersão foi 


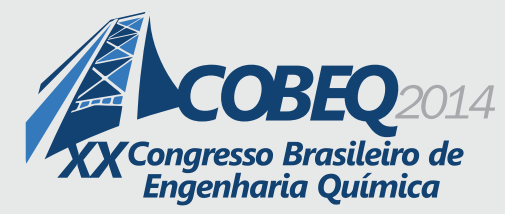

19 a 22 de outubro de 2014

Florianópolis/SC

preparada com agitação mecânica constante, adicionando gradualmente a argila em um recipiente com água destilada, após a adição estar completa a agitação foi continuada durante 20 minutos. Foi aplicado um tratamento sódico com $\mathrm{Na}_{2} \mathrm{CO}_{3}$, sob agitação e aquecimento a $95^{\circ} \mathrm{C}$, a dispersão. Depois de resfriar a dispersão foi realizado o tratamento com o sal quaternário de amônio, adicionando uma taxa de $100 \mathrm{meq} / 100 \mathrm{~g}$ de argila, e agitado por 30 minutos. Após agitação, a dispersão foi filtrada através de um funil de Buchner, acoplado a uma bomba a vácuo, usando papel de filtro normal. O material foi lavado, sucessivamente, com $4 \mathrm{~L}$ de água destilada. $\mathrm{O}$ material foi seco a $60^{\circ} \mathrm{C} \pm 5^{\circ} \mathrm{C}$ durante 24 horas e caracterizado. Método utilizado por Pereira $e t$ al. (2007).

As amostras foram nomeadas como ABOG e ABOD, levando-se em consideração os sais quaternários de amônio, em que: $\mathrm{AB}$ indica argila Bofe; $\mathrm{O}$ designa organofílica; $\mathrm{G}$ corresponde a Genamin; D indica Dodigen.

\subsection{Caracterização}

Difração de raios X (DRX): As amostras de argilas foram peneiradas e colocadas em porta amostra de alumínio para as medições de difração de raios-X. Os padrões de DRX dos materiais foram obtidos no equipamento Shimadzu XRD-6000 com radiação $\mathrm{CuK \alpha} \alpha$, tensão de $40 \mathrm{KV}$, corrente de $30 \mathrm{~mA}$, tamanho do passo de 0,020 $2 \theta$ e tempo por passo de 1,000 s, com velocidade de varredura de $2^{\circ}(2 \theta) / \mathrm{min}$, com ângulo $2 \theta$ percorrido de 2 a $50^{\circ}$.

Inchamento de Foster: Este teste é utilizado para verificar a afinidade do sal quaternário com as moléculas orgânicas de solvente conforme Valenzuela-Diaz (1994), que são baseados na norma ASTM D 5890-95. Consiste em colocar em uma proveta de $100 \mathrm{~mL} 1,0 \mathrm{~g}$ da argila organofílica em $50 \mathrm{ml}$ de solvente sem agitação. Em seguida, o sistema é deixado em repouso durante 24 horas. Depois, o período de repouso foi medido pelo volume ocupado pela argila (inchaço sem agitação). Seguidamente, o conteúdo da proveta é agitado, com um bastão de vidro durante 5 minutos, e deixado novamente em repouso. Após 24 horas, volume ocupado pela argila (inchaço com agitação) é aferido. Os solventes orgânicos testados foram: gasolina, óleo diesel e querosene comercial.

Capacidade de Adsorção: O teste de avaliação da capacidade de adsorção em solvente orgânico foi baseado no "Standard Methods of Testing Sorbent Performance of Adsorbents" baseado nas normas ASTM F716-82 e ASTM F726-9. Este teste constou do seguinte procedimento: em um recipiente, béquer, onde foi colocado o solvente a ser testado até uma altura de $2 \mathrm{~cm}$. Em uma cesta (fabricada de tela de Aço Inoxidável com malha ABNT 200, abertura de $0,075 \mathrm{~mm}$ ) foi colocado $1,00 \mathrm{~g}$ do material adsorvente, argila organofílica a ser testado. Esse conjunto foi pesado e colocado no béquer com o solvente, onde permaneceu em contato 15 minutos. Após esse tempo, deixou escorrer o excesso por 15 segundos e realizada uma nova pesagem. A quantidade de solvente adsorvida foi calculada a partir da Equação (1). 


$$
A d=\left(\frac{P_{1}-P_{2}}{P_{2}}\right) * 100
$$

Em que: $P_{1}$ : Peso do material após adsorção. $P_{2}$ : Peso do material adsorvente seco. Ad: Eficiência da adsorção para o fluido e o adsorvente testado, em percentagem.

Preparo das Emulsões óleo/água: Para a realização dos ensaios de remoção em banho finito, foram produzidas emulsões óleo/água. O óleo utilizado foi o óleo lubrificante, da marca Lubrax. Foi adicionado às emulsões cloreto de sódio na concentração de $5000 \mathrm{mg} . \mathrm{L}^{-1}$ para simular a salinidade da água do mar. As emulsões foram preparadas sob agitação intensa (17000 rpm), rotação suficiente para a formação das emulsões, durante 20 minutos. Os ensaios Consistiu em adicionar 0,5 g de argila organofílica a $50 \mathrm{~mL}$ das emulsões com concentrações de 100, 300 e 500 mg.L $L^{-1}$. Após adicionar, levou-se o conjunto (emulsão óleo/água + argila organofílica) para a agitação mecânica, variando entre 0,100 e $200 \mathrm{rpm}$ durante 6 horas, de forma a garantir o equilíbrio do sistema e posteriormente quantificado pelo método do clorofórmio o mesmo utilizado por Cunha (2012).

\section{RESULTADOS}

Na Figura 2 estão ilustrados os difratogramas das argilas ABOG e ABOD apresentam as aberturas das camadas das argilas, logo após a intercalação dos cátions orgânicos. É possível verificar que após o processo de organofilização ocorreu a redução do ângulo $2 \theta$ e, consequentemente, aumento do espaçamento basal decorrente do sal quaternário de amônio, promovendo uma nova abertura nas argilas.

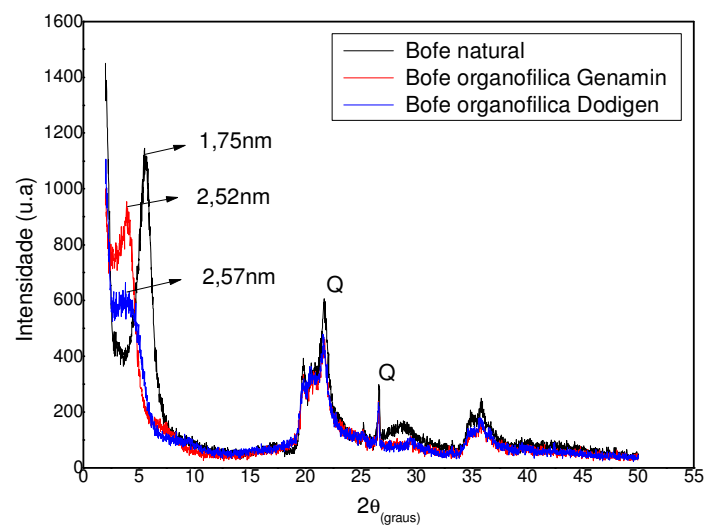

Figura 2 - Difratogramas das argilas ABOG e ABOD. 


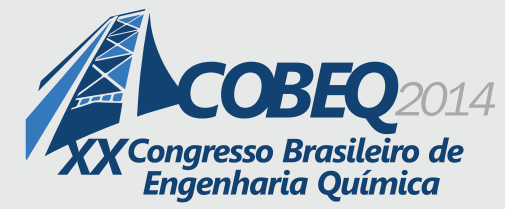

Por meio dos difratogramas é possível verificar que a argila Bofe natural apresenta reflexão do grupo da esmectita (E) que aparece em aproximadamente $5,6^{0}$ e corresponde ao espaçamento basal (d001) de 1,75nm que é característico de uma montmorilonita hidratada. Observam-se também outros picos que são referentes à mineral não esmectítico como o quartzo que se apresenta como impureza, características encontradas também por Shen, (2001). Na representação gráfica para as argilas tratadas, pode-se observar que os padrões de DRX, ilustram que após a modificação da argila Bofe natural com sais quaternários de amônio (Genamin e Dodigen), o deslocamento dos picos de difração ocorreu um aumento do espaçamento basal para $2,52 \mathrm{~nm}$, e 2,57nm, O aumento expressivo na $\mathrm{d}(001)$ das amostras obtidas com os sais quaternários evidencia a efetiva intercalação dos cátions quaternários de amônio nas camadas interlamelares das argilas. Essa expansão da camada da argila também foi encontrada por Silva et al. (2007). Constata-se uma diferença de valores de espaçamento basal entre as duas argilas organofílicas. Esta diferença é de $0,05 \mathrm{~nm}$ e pode ser explicada pelas diferentes estruturas dos sais quaternários de amônio, conforme foi mostrado na Figura 1.

Os resultados apresentados na Figura 3(a, b) indicam a afinidade das argilas organofílicas tratadas com sais quaternários de amônio (Genamin e Dodigen), em solventes orgânicos.
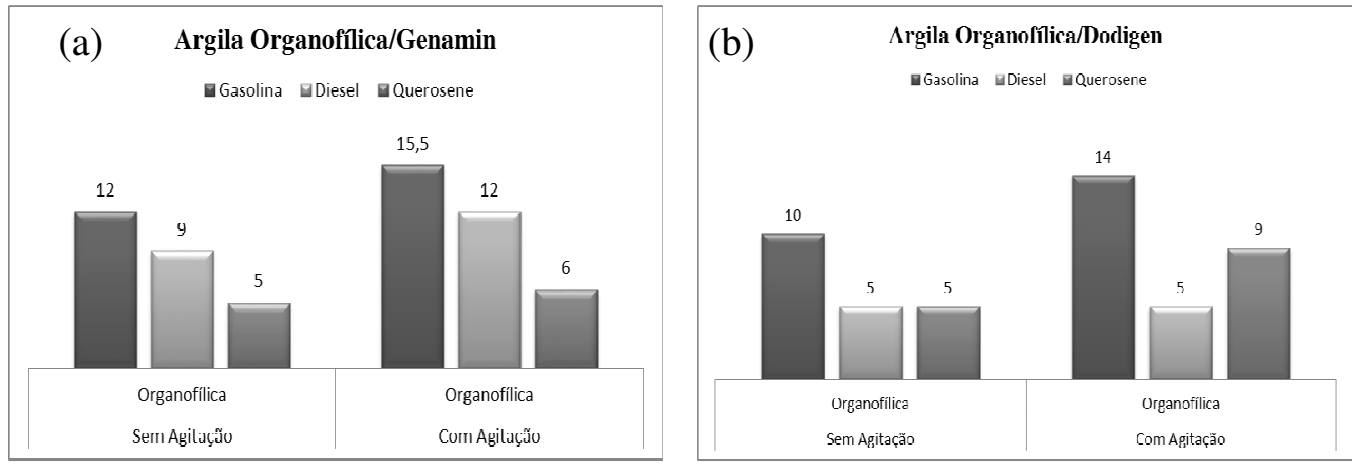

Figura 3 - Inchamento de Foster da argila ABOG (a) e argila ABOD (b) com ou sem agitação em solventes orgânicos.

É possível observar que a argila ABOG possui uma maior afinidade com compostos orgânicos quando comparados com os resultados da argila ABOD. Esta afinidade possui mais evidência com o solvente gasolina, principalmente após a agitação. No entanto a argila ABOD obteve maior afinidade com a gasolina sem e com agitação quando relacionados com os outros solventes. Com a agitação há maior contato do material com o solvente, comportamento semelhantes foram encontrados em outros estudos Rodrigues et al. (2010).

Os resultados referentes as análises da capacidade de adsorção para as argilas natural e tratadas com os diferentes sais (Genamin e Dodigen) são apresentados na Figura 4. 


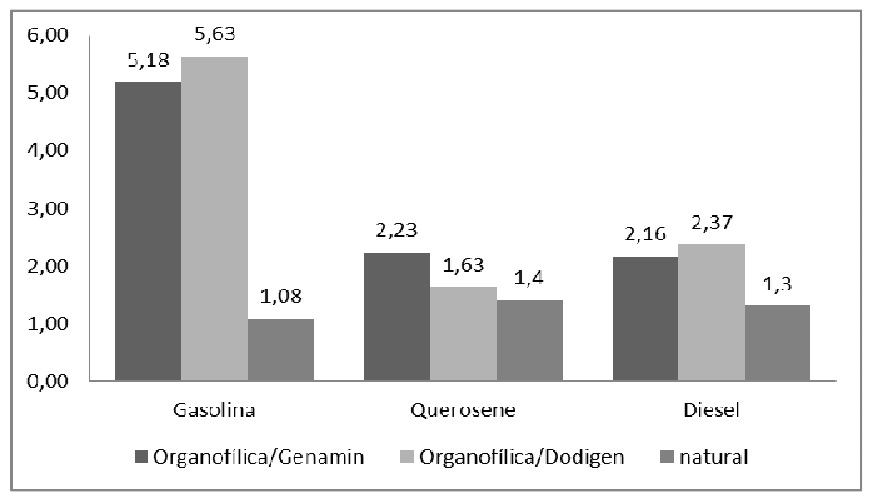

Figura 4 - Capacidade de adsorção de gasolina, óleo diesel e querosene.

Os resultados de capacidade de adsorção com gasolina para a argila Bofe natural apresentou a capacidade de adsorver $1,08 \mathrm{~g}$ do solvente por cada grama de argila; as argilas organofílicas (ABOG e ABOD), apresentaram capacidades de 5,18 g/g, e 5,63 g/g. Observa-se que a capacidade de adsorção em diesel para a argila Bofe sem tratamento adsorveu $1,30 \mathrm{~g} / \mathrm{g}$; as argilas organofílicas (ABOG e ABOD), apresentaram capacidades de 2,16 g/g, e 2,37 g/g. Verifica-se que a capacidade de adsorção em querosene para a argila Bofe sem tratamento adsorveu 1,40 g/g; as argilas organofílicas (ABOG e ABOD), apresentaram capacidades de 2,23 $\mathrm{g} / \mathrm{g}$ e $1,63 \mathrm{~g} / \mathrm{g}$.

Observa-se que após o tratamento com os surfactantes (Genamin e Dodigen) houve um aumento na capacidade de adsorção da argila Bofe, É evidente a influência da estrutura do surfactante sobre as propriedades das argilas organofílicas.

Na Tabela 1 encontram-se os resultados referentes ao potencial de remoção de emulsões óleo/água utilizando as argilas organofílicas com diferentes sais, obtendo como resposta à percentagem de remoção de óleo lubrificante e a capacidade de remoção no equilíbrio, de acordo com o planejamento fatorial $2^{2}$ com três pontos centrais no total de 7 experimentos.

Tabela 1 - Resultados obtidos a partir do Planejamento Fatorial $2^{2}$ com três pontos centrais para remoção de óleo lubrificante, utilizando as argilas organofílicas (ABOG e ABOD).

\begin{tabular}{|c|c|c|c|c|c|c|}
\hline \multirow[b]{2}{*}{ Testes } & \multirow[b]{2}{*}{$\begin{array}{c}\mathrm{C}_{0}\left(\mathrm{mg} \mathrm{L}^{-1}\right) \\
\text { Teórica }\end{array}$} & \multirow[b]{2}{*}{ Agitação } & \multicolumn{2}{|c|}{ ABOG } & \multicolumn{2}{|c|}{ ABOD } \\
\hline & & & \% Rem & $\begin{array}{c}\text { qeq } \\
\left(\mathrm{mg.g}^{-1}\right)\end{array}$ & \% Rem & $\begin{array}{c}\text { qeq } \\
\left(\mathrm{mg.g}^{-1}\right)\end{array}$ \\
\hline 1 & 100 & 0 & 98,09 & 9,42 & 64,62 & 6,46 \\
\hline 2 & 500 & 0 & 99,26 & 49,63 & 96,07 & 48,03 \\
\hline 3 & 500 & 200 & 99,97 & 49,98 & 95,29 & 47,64 \\
\hline 4 & 100 & 200 & 94,87 & 9,11 & 78,09 & 7,81 \\
\hline 5 & 300 & 100 & 99,78 & 30,53 & 90,69 & 27,21 \\
\hline 6 & 300 & 100 & 98,96 & 30,28 & 87,58 & 26,28 \\
\hline
\end{tabular}




\begin{tabular}{l|l|l|l|l|l|l}
$\mathbf{7}$ & 300 & 100 & 99,78 & 30,53 & 89,02 & 26,71 \\
\hline
\end{tabular}

A Tabela 1 mostra os resultados obtidos nos diferentes ensaios, obedecendo ao planejamento experimental $2^{2}$, onde o melhor resultado em relação à percentagem de remoção total de óleo foi no ensaio 3 (500ppm e 200rpm) com 99,97 \% de remoção e verifica-se também a melhor capacidade de remoção de óleo no equilíbrio, onde 49,98 mg de óleo são removidos para cada grama de argila organofílica tratada com o sal orgânico Genamin. Avaliando a argila ABOD é possível observar que a argila consegue remover $96,07 \%$ da concentração inicial de óleo em emulsão, com capacidade de remoção de óleo no equilíbrio de $49,98 \mathrm{mg} \cdot \mathrm{g}^{-1}$.

\section{CONCLUSÃO}

Argilas organofílicas foram obtidas a partir de argilas Bofe preparadas com dois diferentes tipos de sais quaternários de amônio: cloreto de cetil trimetil amônio e cloreto de alquil dimetil benzil amônio e avaliadas na remoção de óleo/água (contaminante orgânico). Os resultados de DRX mostraram a evidência da intercalação dos sais quaternários de amônio na estrutura da argila Bofe. Os testes de capacidade de adsorção em solventes orgânicos demonstraram que as argilas organofílicas (ABOG e ABOD), apresentaram maior capacidade de adsorção nos solventes testados quando comparada com a argila natural. A eficiência de remoção da argila (ABOG) foi superior a encontrada para argila (ABOD). As argilas (ABOG e ABOD) podem efetivamente remover óleo de emulsão óleo/água.

\section{REFERÊNCIAS}

BENITO, J.M.; RIOS , G.; PASOZ, C.; COCA, J. Methods for the separation of emulsified oil from water: a state-of-the-art review. Trends Chem. Eng. v. 4, p.203-231, 1998.

CUNHA, R. S. S. Obtenção de argila organofílica visando o processo de descontaminação de águas oleosas. Dissertação, Departamento de Engenharia Química da Universidade Federal de Campina Grande, 2012.

GIL. A.; F. ASSIS.; S. ALBENIZ.; S. KORILI. Removal of dyes from waste water by adsorption on clays pillared. Chem. Eng. J. v.168, p. 1032-1040, 2011.

LAGALY, G.; BERGAYA, F.; THENG, B. K. G. Handbook of Clay Science. Developments in Clay Science, Elsevier Science, Amsterdam, v. 1, 2006.

PEREIRA, K. R. O.; RODRIGUES, M. G. F.; VALENZUELA-DIAZ, F. R. Síntese e caracterização de argilas organofílicas: comparação no uso de dois métodos. Rev. Elet. Mat. Proc, v. 2, p. 1-8, 2007. 
RAJAKOVIC, V.; ALEKSIC , G.; RADETIC , M.; RAJAKOVIC , L.; Efficiency of oil removal from real wastewater with different sorbent materials, J. Hazard. Mater. v.143, p. 494-499, 2007.

RAMOS VIANNA, M. M. G. Characterization and study of sorptive properties of differently prepared organoclays from a brazilian natural bentonite. J. Thermal Analysis and Calorimetry, v.82, p. 595-602, 2005.

RODRIGUES, S. C. G.; RODRIGUES, M. G. F.; PEREIRA, K. R. O.; ALENZUELA-DÍAZ, F. R. Performance or organophilic Clay as adsorbent in the oil/water separation process. Oil Gas J. B. v.4, p.49-58, 2010.

SHARIFF I.; WANG, S.; ANG, H. M. Removal of emulsified oil from oily wastewater using agricultural waste barley straw. J. Biochemical Eng. v. 49, p 78-83, 2010.

SHEN, Y.H. Preparation of organobentonite using nonionic surfactants". Chemosphere. v. 44, p. 989-995, 2001.

SILVA A, R. V.; FERREIRA H. C. Argilas bentoníticas: conceitos, estruturas, propriedades, usos industriais, reservas, produção e produtores/fornecedores nacionais e internacionais. Rev. Elet. Mat. Proc, v. 3.2, p. 26-35, 2007.

SILVA, M. M.; PATRÍCIO, A. C. L.; LIMA, W. S.; LABORDE, H. M.; RODRIGUES, M. G. F. Preparação e avaliação da argila verde organofílica usando diferentes concentrações de surfactante catiônico visando seu uso na separação óleo/água. Scientia Plena, v. 7, p.171-180, 2011.

VALENZUELA-DIAZ F. R. Preparação em nível de laboratório de algumas argilas esmectíticas organofílicas. Tese de Doutorado, Departamento de Engenharia Química da Escola Politécnica da Universidade de São Paulo, 1994.

ZHOU, Y.-B..; X.-Y. TANG.; HU, X.-M.; S. Fritschi.; J. Lu.; Emulsified oily wastewater treatment using a hybrid-modified resin and activated carbon system. Sep. Purif. Technol. v. 63 p.400-406, 2008. 